\title{
Benign thymic cysts in Hodgkin's disease: report of a case and review of published cases
}

\section{R LEWIS, A MANOHARAN}

From the Department of Clinical Haematology, St George Hospital, University of New South Wales, Kogarah, Sydney, Australia

Mediastinal masses are a frequent finding in patients with Hodgkin's disease, and usually represent either mediastinal lymphadenopathy or a diseased thymus gland. ${ }^{1}$ In some rare patients, however, the mediastinal mass may be due to diffuse thymic hyperplasia ${ }^{2}$ or benign thymic cysts. ${ }^{3}$ In each of the 10 reported cases of thymic cysts in Hodgkin's disease, the diagnosis of the thymic cysts was made either during investigations for persistent mediastinal mass after completion of radiotherapy or chemotherapy or during investigation of the mediastinal mass at "relapse."3-7 In this report we describe a patient with Hodgkin's disease in whom thymic cysts were diagnosed at presentation; the cysts resolved completely after effective chemotherapy.

\section{Case report}

A 26 year old man presented in August 1984 with a nine month history of swelling of the left side of the neck, associated with alcohol induced pain in the left cervical region, severe night sweats and fevers, and weight loss of $7 \mathrm{~kg}$.

Physical examination showed widespread lymphadenopathy affecting the left cervical, bilateral supraclavicular, and left axillary regions. There was no hepatosplenomegaly or any clinical evidence of superior vena cava obstruction.

Excision biopsy of a left cervical lymph node showed histological features of nodular sclerosing Hodgkin's diseasesubstantial interconnecting bands of collagenous fibrous tissue surrounding nodules of mixed cellularity with many lacunar cells. An initial chest radiograph showed a massive anterior mediastinal mass (fig 1), and computed tomographic scanning of the thorax showed the mass to have large areas of solid tumour and several loculated cystic areas (fig 2). A fine needle aspiration of one of these cysts yielded serous fluid and, although several large mononuclear cells were seen on microscopic examination, there were no diagnostic Reed-Sternberg cells. There was also no evidence of any underlying tissue necrosis. An abdominal computed tomography scan was normal, as were the results of other staging investigations.

The staging indicated IIB Hodgkin's disease and chemotherapy with MOPP (nitrogen mustard, vincristine, procarbazine, and prednisone) was started. At the completion

Address for reprint requests: Dr A Manoharan, St George Hospital, Kogarah, NSW 2217, Australia.

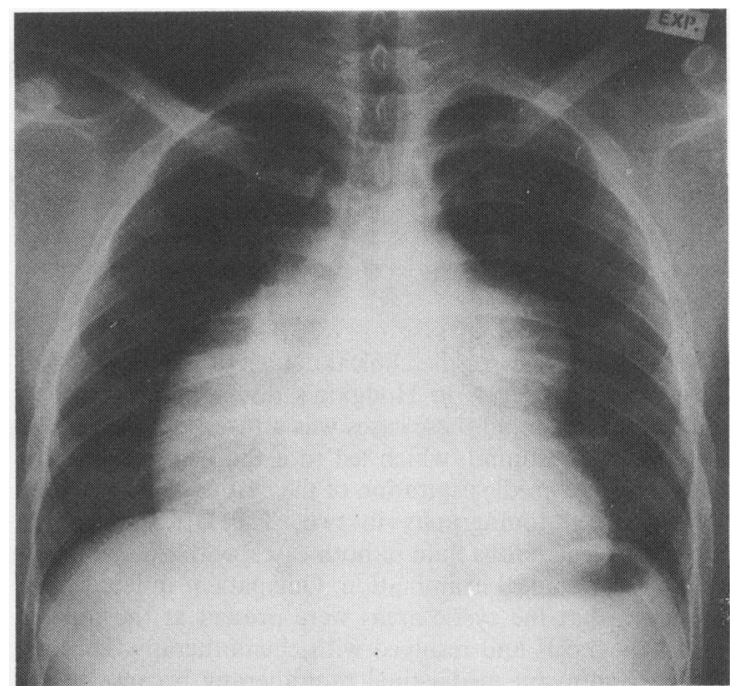

Fig 1 Chest radiograph showing mediastinal mass.

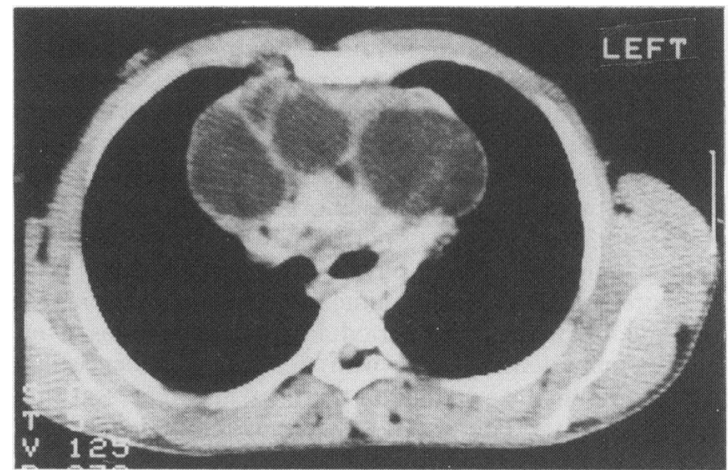

Fig 2 Thoracic computed tomography scan $(2.5 \mathrm{~cm}$ below the manubriosternal joint) showing areas of tumour and several translucent cystic areas.

of six courses of treatment, there was complete resolution of clinical lymphadenopathy and repeat thoracic computed tomography showed normal appearances. He subsequently received adjuvant radiotherapy to the mediastinal region. Ten months after completion of radiotherapy he remains well and disease free. 
Benign thymic cysts in Hodgkin's disease: review of published cases

\begin{tabular}{|c|c|c|c|c|c|c|}
\hline \multirow{2}{*}{$\begin{array}{l}\text { Patient } \\
\text { No. }\end{array}$} & \multirow[b]{2}{*}{ Sex/age $(y)$} & \multicolumn{2}{|c|}{ Hodgkin's disease } & \multirow[b]{2}{*}{ Treatment } & \multirow[b]{2}{*}{ Diagnosis of thymic cysts } & \multirow{2}{*}{ Reference } \\
\hline & & Histology & Stage & & & \\
\hline 1 & M/29 & MC & IIB & DXRT/vinblastine & At thoracotomy for residual mediastinal mass & 3 \\
\hline 2 & F/25 & NS & IIB & $\begin{array}{l}\text { MOPP/DXRT/ } \\
\text { vinblastine }\end{array}$ & At thoracotomy for residual mediastinal mass & 3 \\
\hline 3 & $\mathbf{F} / 40$ & NS & IIB & $\begin{array}{l}\text { MOPP/DXRT/ } \\
\text { vinblastine }\end{array}$ & At thoracotomy for residual mediastinal mass & 3 \\
\hline 4 & $\mathrm{M} / 17$ & $\mathrm{MC}$ & NR & DXRT/COPP & At necropsy after persistent mediastinal mass & 4 \\
\hline $\begin{array}{l}5 \\
6\end{array}$ & $\mathbf{M} / 23$ & MC & IIIB & MOPP/DXRT & At thoractomy for new mediastinal mass & 4 \\
\hline 6 & M/29 & MC & IA & $\begin{array}{l}\text { DXRT/MOPP/ } \\
\text { ABVD }\end{array}$ & $\begin{array}{l}\text { At thoractomy after CT showed persisting } \\
\text { mediastinal mass in relapse not responding }\end{array}$ & 4 \\
\hline 7 & $\mathbf{F} / 21$ & NS & IIA & MOPP & At thoracotomy for persistent mediastinal mass & 5 \\
\hline 8 & $\mathbf{F} / 23$ & NS & IIA & DXRT & At thoracotomy for increasing mediastinal mass & 6 \\
\hline 9 & F/28 & NS & IIA & DXRT & At thoracotomy for increasing right hilar mass & 6 \\
\hline 10 & $\mathbf{M} / 39$ & NS & NR & DXRT/MOPP & $\begin{array}{l}\text { FNAB of cystic lesion on CT scan for increasing } \\
\text { mediastinal mass }\end{array}$ & 7 \\
\hline 11 & $\mathbf{M} / 26$ & NS & IIB & MOPP & FNAB of cystic lesion on CT scan at presentation & This repo \\
\hline
\end{tabular}

MC-Mixed cellularity; NS - nodular sclerosing; DXRT_radiotherapy; MOPP_nitrogen mustard, vincristine, procarbazine, prednisone: COPP - cyclophosphomide, vincristine, procarbazine, prednisone; ABVD —adriamycin, bleomycin, vinblastine, DTIC; FNAB-fine needle aspiration biopsy; CT—computed tomography.

\section{Discussion}

The table summarises the clinical details of the 11 reported cases of thymic cysts in Hodgkin's disease. The common clinical feature in all these cases was a mass localised in the anterior mediastinum, which led to a thoracotomy in nine cases and fine needle aspiration of the cystic lesions revealed by computed tomography in two. The latter procedure yielded a clear serous fluid in both cases, with no malignant cells on cytological examination. Our patient differed from others in that the cystic areas were present at the time of initial diagnosis and resolved with chemotherapy. He then received adjuvant mediastinal radiotherapy because of the increased risk of local relapse in patients with bulky mediastinal masses.

Thymic cysts apparently may accompany active Hodgkin's disease, either at initial presentation or at relapse, or may manifest themselves after completion of effective treatment. The pathogenesis of thymic cysts in patients with Hodgkin's disease is not clear. The suggestion that the cystic changes represent treatment induced degeneration of the disease is not relevant to our patient. Furthermore, in at least some of the previously reported patients from the days before computed tomography, the thymic cysts could have been present at the time of initial presentation and persisted throughout the treatment period. Finally, the cysts, as in our patient, may actually clear with treatment-evidence that tends to refute the explanation that they may represent simple thymic cysts. This also raises the possibility that, among patients previously treated who had a large mediastinal mass. detected by routine radiography alone, some may have has cystic areas that also resolved after treatment.

The presence of thymic cysts in patients with Hodgkin's disease appears to have no clinical importance, provide that it is recognised. It may present a diagnostic difficulty and if the finding is interpreted as representing residual of progressive disease, further treatment may increase the lik lihood of illness and death. The use of thoracic computed tomography and fine needle biopsy may offer accurate diag nosis without major surgical intervention.

\section{References}

1 Keller AR, Castleman B. Hodgkin's disease of the thymus glan£ Cancer 1974;33:1615-23.

2 Tartas NE, Korin J, Dengra CS, Barazzutti LM. Diffuse thymit enlargement in Hodgkin's disease. JAMA 1985;254:406.

3 Katz M, Piekarski JD, Bayle-Weisgerber C, Laval-Jeantet Teillet $F$. Residual mediastinal mass following radiation the? apy for Hodgkin's disease. Am Radio 1977;20:667-72.

4 Baron RL, Sagel SS, Baglan RJ. Thymic cysts following radiation therapy for Hodgkin's disease. Radiology 1981;141:593-7.

5 Anonymous. Case records of the Massachusetts General Hospitif (Case 47, 1982]. N Engl J Med 1982;307:1391-7.

6 Murray JA, Parker AC. Mediastinal Hodgkin's disease and thyo mic cysts. Acta Haematol 1984;71:282-4.

7 Kin HC, Nosher J, Haas A, Sweeney W, Lewis R. Cystic degenefro ation of thymic Hodgkin's disease following radiation therap Cancer 1985;55:354-6. 